\title{
Female Managers in Japan: How to Set the Goal of Increasing Women in Leadership Roles
}

\author{
Lau Chung Ming \\ Correspondence: Lau Chung Ming, Japan. Email: klau728@yahoo.co.jp \\ Received: April 15, 2019 \\ doi:10.11114/bms.v5i2.4279 \\ Accepted: May 15, 2019 Online Published: May 20, 2019 \\ URL: https://doi.org/10.11114/bms.v5i2.4279
}

\begin{abstract}
How to increase the number of female manager is still one of the contemporary issues in Japan. In comparison with other developed countries, Japan is far below others in terms of the level of employing women as management staffs. This paper was undertaken to shed light on the factors hindering the promotion of female manager in Japan workforce. It was also intended to discover more relevant improvement area that Japan government can consider to put more efforts in order to enhance the Japanese women for working as senior positions. The perspective of employee and employer are adopted for discussing and illustrating important insights which are considered able to explain the current phenomenon in Japan. On the other hand, a question from the survey of human resources management in Japanese companies in China (JCCs) which was conducted previously is used to further test if the factors of industry, location, company size, and years of business have any influence on the degree of employing women in management position of Japanese companies in China. According to the result by analyzing 180 valid response, 113 from Mainland China and 67 from Hong Kong, companies in servicing industries are likely to have higher percentage of female manager than those in manufacturing industries. A positive association existed between the industrial factor and percentage of female managers in JCCs.
\end{abstract}

Keywords: Japanese women, management, manufacturing, servicing, Mainland China, Hong Kong

\section{Introduction}

Although increasing the labor participation of women was regarded as one of the significant changes in Japan's labor force in recent years, there are still considerable obstacles to women's senior management positions. The reality shows that the Executive Committee is still reluctant to accept women's entry no matter of their performances and qualifications (Izraeli and Adler, 1994). Previous studies have tried to clarify any particular reasons for women's lack of promotion to management positions. Men have historically had greater access to power, privilege and wealth than women in most societies. Another important barrier to women advancement in their career path in most industrialized countries is the persistent stereotype that associates management with men. In addition, for overseas management, official organizational rules have certain influences on informal procedures, which may put the difficulties on female manager to involve in global business projects (Linehan, 2006).

Japan cannot be excluded from such circumstance regarding women in the workplace and in management positions facing stresses from the Western influence on Japanese society. Although the low level of participation of women in management is still worldwide issue, the situation in Japan is quite grave and necessary to be concerned in comparison to other countries. According to the statistic made by OECD.Stat (2015), Japan had nearly the lowest level of the percentage of women on boards of directors amongst Forbes Global 500 companies, and was far from the average figure (see Figure 1). Even though Prime Minister Shinzo Abe put a lot of efforts making plans for promoting more women to senior positions in order to achieve the target of the female managers' ratio to $30 \%$ by 2020 , the result is not satisfactory. 


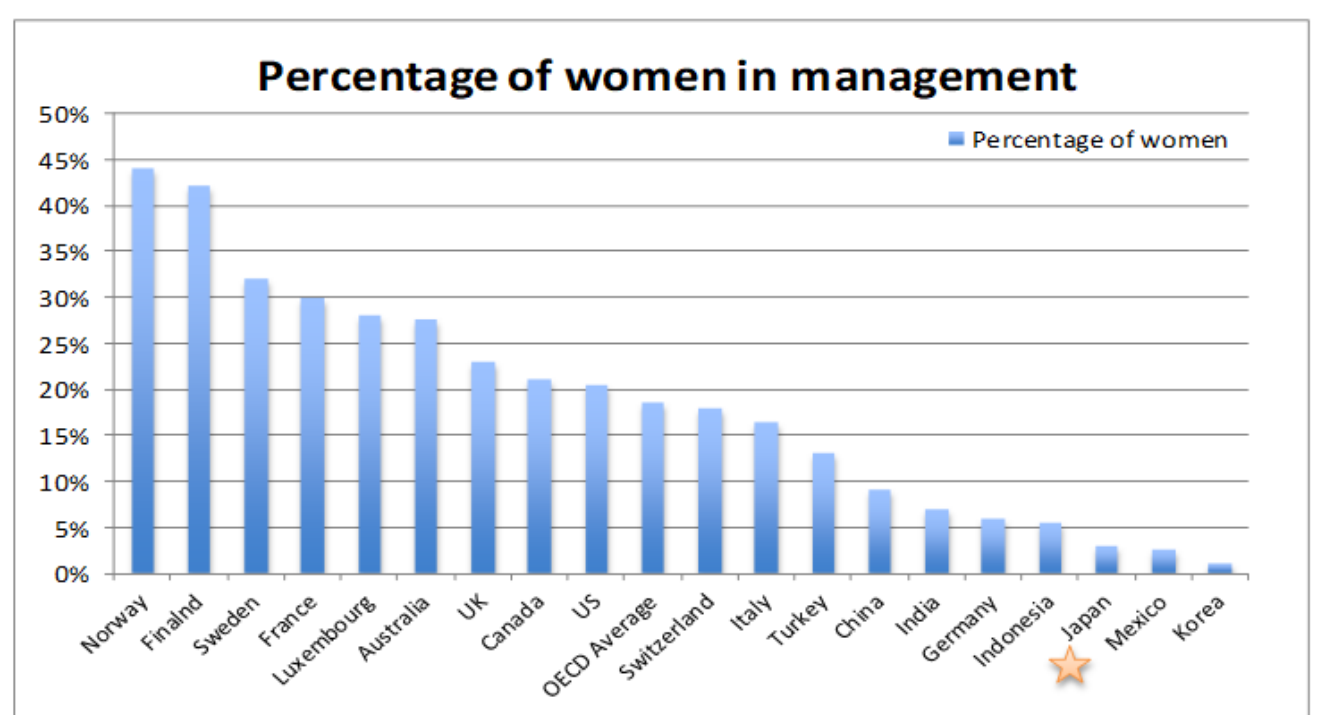

Figure 1. Share of women on boards of directors (Forbes Global 500 companies)

Source: OECD Stat (2005)

Regarding the discussion of gender difference and low level of female managers in Japan, there were many former articles on related arguments. Since it is still a critical issue faced by Japan government, it is worth exploring more insights from different angles. In fact, some fundamental difficulties of increasing the ratio of female managers, like gender difference, or family pressures, are quite similar as comparing with other countries. The reasons why Japan is still unable to break through and behind others should be considered including another different perspectives. Therefore, this paper is undertaken and arranged by two approaches. At first, an exploratory approach is adopted to review previous available literatures and research data. In addition, current conditions of labor legislation, living style, and common practice in Japan are discussed. In light of the difference of traditional culture, custom, and labor regulation between Japan and other Asian countries, the relevant comparison and analysis are summarized into the employee's perspective and employer's perspective for the purpose of exploring some idea of improving the fundamental problems of female working environment in Japan. Secondly, a descriptive research with data analysis of investigating the adoption rate of female managers of Japanese companies in China is used to explore more information of the low rate of female managers. Following an explanation of the research design, findings from the analysis reveal the affection of the industries and other factors to the level of female managers is employed. The paper ends with a conclusion with recommendations which are expected to contribute to improve the development of female manager in Japan.

\section{Literature Review}

The business environment tends to be mercurial and complex nowadays. Diversity becomes key to business success. In order to survive and develop further, companies today need to be more productive, more innovative and in many ways more open. Meanwhile, risk management, which includes the process of identifying, evaluating and managing uncertainty, is also a vital factor to the smooth operation in daily business. Men and women are expected to perceive and respond to risk in different ways, contrasting in how they balance speed and decisiveness with careful consideration. Numerous researches indicating the group-think should be avoided due to the homogenous leadership members. In order to understand well the customers and get the potential new market opportunities, a high proportion of women leader is necessary to be included (Grant Thornton, 2017).

The study conducted by Grant Thornton compared the result of giant companies globally in terms of the mixture of director boards. One of the findings indicates that companies with male-only boards in the UK (FTSE 350), US (S\&P 500 ) and India (CNX 200) are foregoing potential profits of $\$ 655 \mathrm{bn}$, while in the UK and US alone moving to mixed boards on the S\&P 500 and the FTSE 350 could boost GDP by around 3\%". Although evidence demonstrates diversity is a prerequisite of performance improvement, about a third of companies still have no women in senior management and the gender diversity in leadership is improving at a slow pace that hit $25 \%$ in year 2017 , an increase of only one percent since 2016 (Grant Thornton, 2017). The considerable barriers still exist for women moving to senior management position. However, the worry of few Japanese women in management is more serious in comparison of the worldwide average (Scullion \& Collings, 2006; Sonoda, 2013).

There is undeniable that the increase of women workforce participation or number of seniors has many potential contributions to the Japanese economy. Besides, higher participation of workforce can induce and stimulate the desire of consumption due to higher household income. Unfortunately, the percentage of company presidents who are women 
was just 7.8 percent at the end of April in 2018, even though the prevalence of female chiefs has risen from 5.5\% since 1998. On the other hand, only 5 percent of senior roles including chief executive officers, managing directors, chairs and other senior decision-makers at mid- to large-size Japanese companies were held by women, compared to 23 percent across the greater Asia-Pacific region. This research conducted by the Teikoku Databank in which Baird indicated that the size of the organization is a significant indicator of how likely it is for women to be promoted as a top management position and women tend to have larger representation at the head of small- to mid -size companies. As of 2018, 10.8 percent of companies with sales turnover of under $¥ 50$ million were managed by women, in comparison with only 1.3 percent at companies with sales turnover of over $¥ 10$ billion (Baird, 2018).

With its aging population and shrinking workforce, Prime Minister Shinzo Abe proclaimed the goal of filling 30\% women in leadership positions in Japan by 2020 being unchanged. Government will focus on "Womenomics" to encourage the participation and promote a better role of women in the Japanese workforce. Although Japanese government put a lot of efforts to drive progress in the participation of women in Japan's workforce and advancement of women in management, other observers believe that elements of Japanese culture, including office customs and traditional beliefs regarding gender roles, pose certain challenges for the success of the policy. On the other hand, a law was passed to require large companies to publicly set goals for hiring and promoting women to managerial roles, however, it was criticized 30\% goal might be too ambitious and non-feasible. The persistent stereotype that associates leadership with being male is still considered as a significant hurdle for Japanese women to climb their career ladders. The report highlights that there is still a long way to go according to the latest trends in women's leadership in Japan (Baird, 2018; Grant Thornton, 2017).

\section{Main Causes of Few Japanese Women in Management}

One of Abe's planned structural reforms is a strategy to persuade more Japanese women to join the workforce, to remain in the workforce after they have children, and to advance higher on the career ladder. Indeed, there is an increasing trend of the labor force participation rate of women in Japan (Figure 2). However, Japan's gender gap is one of the largest among high-income countries, and some economists have argued for many years that narrowing this gap is a potential source of economic growth for Japan as well as a way to help offset the long-term demographic problems facing the country. For the purpose of clarifying this dilemma, employee's perspectives and employer's perspective are discussed to illustrate relevant points in next paragraphs.

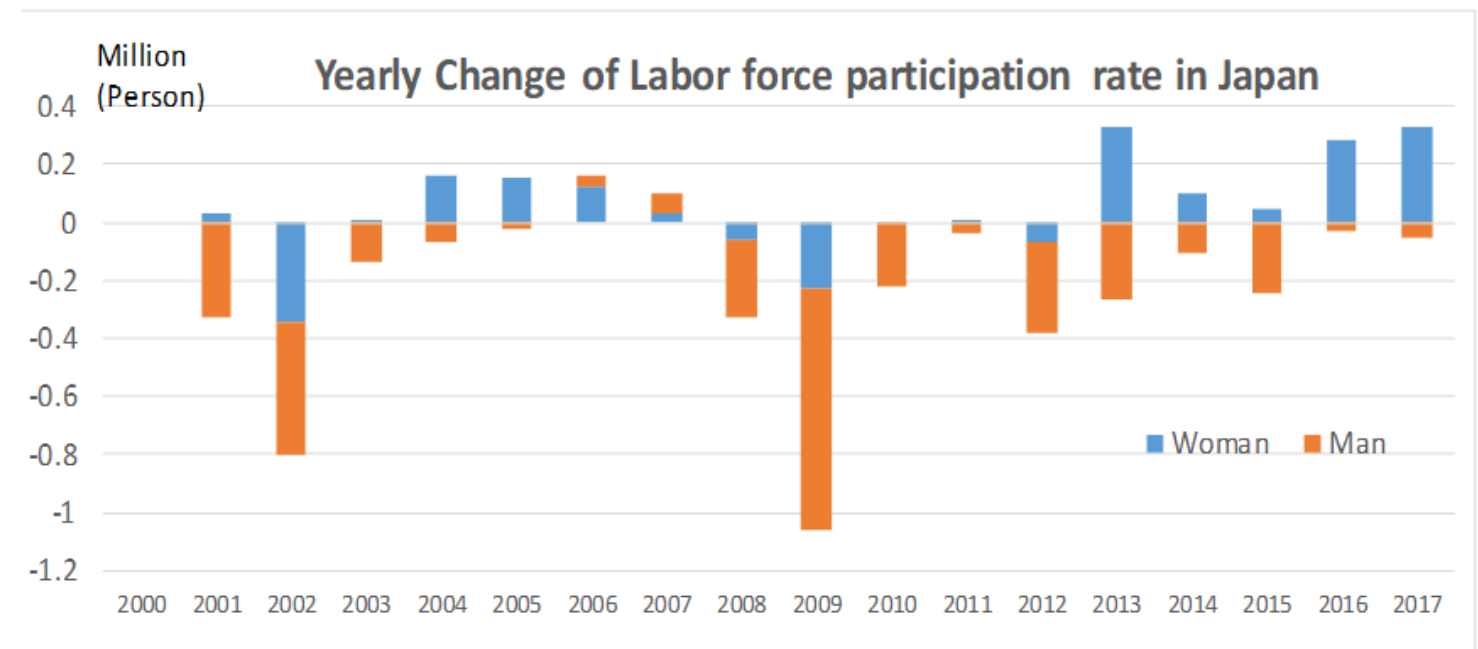

Figure 2. Yearly change of labor force participation rate in Japan

Source: White paper (2018)

\subsection{Employee's Perspective}

The labor force participation rate is the measurement of an economy's active labor force and is calculated by the sum of all employed workers divided by the working age population. According to the statistical data collected by Gender Equality Bureau Cabinet Office in Japan, the female labor force participation rate in Japan (\% of female population ages 15-64) is passable in comparison with the other developed countries (White paper, 2018). Unfortunately, the proportion of female managerial workers in Japan is still far below the average of other countries. Women in Japan are some of the most educated in comparison with other developed countries. It is intriguing that almost half of all Japanese graduates are women, however, only $13 \%$ of managerial position is occupied by women (Figure 3). 


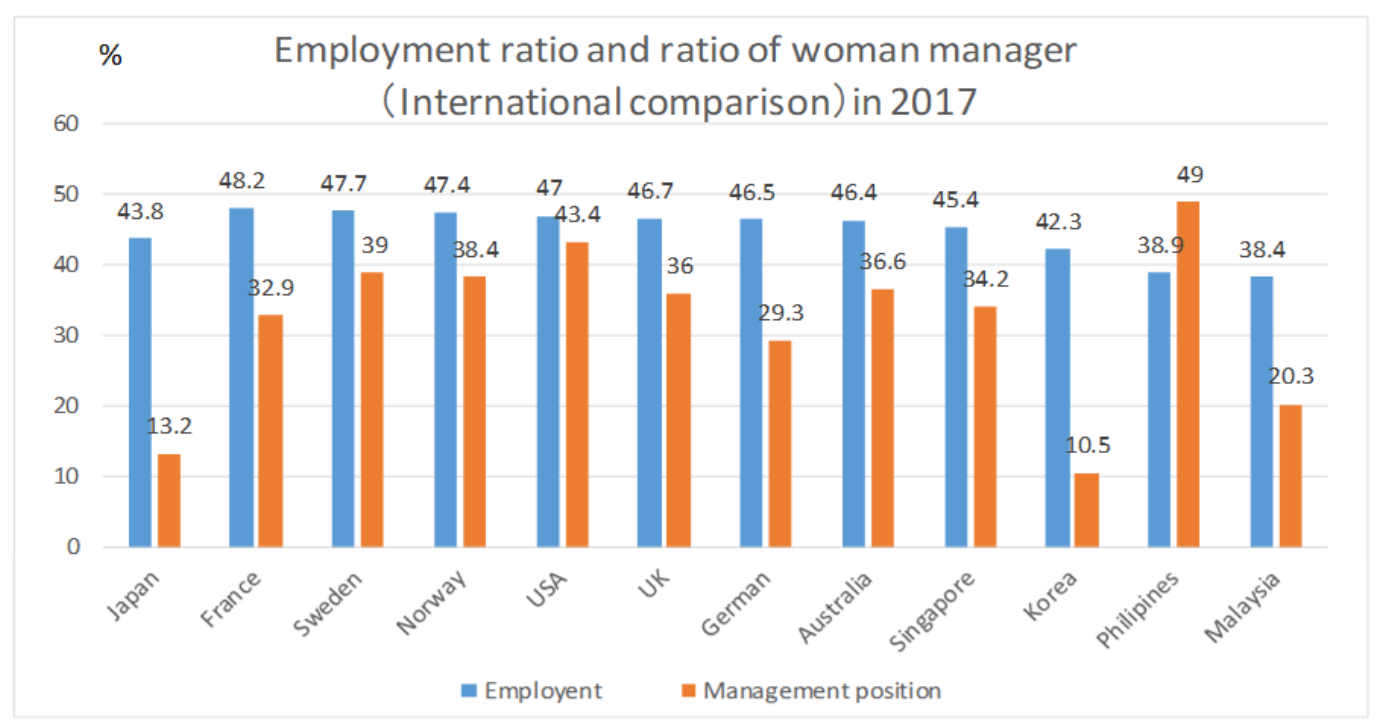

Figure 3. Employment ratio and ratio of woman manager (International comparison)

Source: White paper (2018)

With reference to the regular statistical data by Gender Equality Bureau Cabinet Office, women in Japan has a tendency to participate in work even after they have got any children (White paper, 2018). Figure 4 has shown that the respondents who would like to work continuously even having children had been increased from $26.3 \%$ in 1992 to $55.3 \%$ in 2016. This trend indicates that they do not want only to take care child at home or handle house-keeping works. Even though there is an increasing number of women in Japan who intends to participate in labor market, they do not prefer to find a permanent job. With reference to the Figure 5, over 70\% respondents indicate they would like to work as the part time or contract staff when they look for their jobs. This result imply that they may not be aggressive to involve in their occupation or eager to be successful in their career life (Su, 2015).

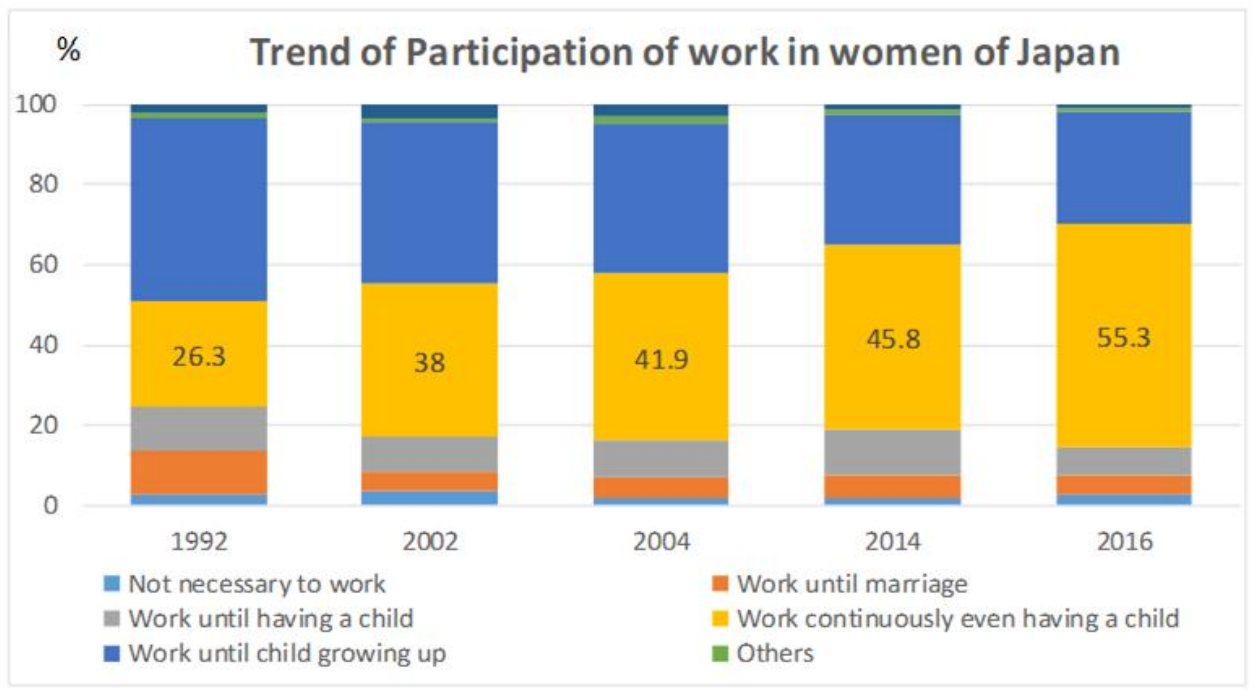

Figure 4. Trend of participation of work in women of Japan

Source: White paper (2018) 


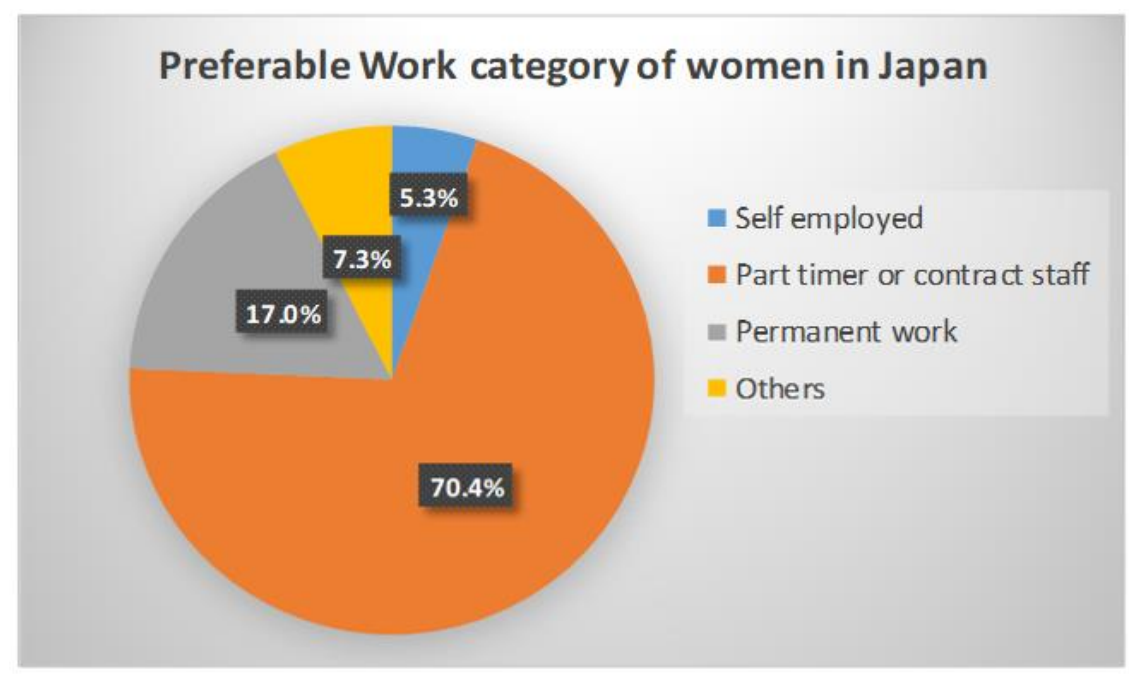

Figure 5. Preferable work category of women in Japan

Source: White paper (2018)

Several scholars highlighted that the obsolete stereotypes, practices and outright discrimination against women are still prevailing in most workplace in Japan. Most women in Japan are facing those problems in general employees, not to speak of being one of management staff. The typical reasons include 1) long working hours, 2) gender role in Japan, and 3) lack of childcare support posing the obstacles to women in Japan about their works and affecting their career path of management. Basically, all those reasons are interrelated and interact on each other.

\section{1) Long Working Hours}

In Japan, long working hours is still a serious social issue for both women and men. This is a country where is commonly known that many cases of "karōshi", or death by overwork is regularly reported in the news. The problem of long working hours is a complex issue that has many facets to it. Part of it has to do with the different expectations of Japanese families about working hours, and other reasons may be due to the expectations of Japanese companies, in which putting in long hours still tends to be viewed as a sign of devotion and hard work rather than of poor time management. Actually, several Asian countries tend to work the long hours, not only the unique phenomenon in Japan. According to the research of OECD.Stat (2015), South Koreans work the second-longest hours among OECD countries, worked 2,124 hours average per each employee in 2014. On the other hand, Singapore also claimed that their employees work the longest hours in the world at 44.9 paid hours a week or 2,334.8 hours a year according to the latest Ministry of Manpower (MOM); and 36\% higher than Japan's 1,710 hours a year (Chia, 2018). Besides, research by UBS Prizes and Earnings 2015 also indicate that Hong Kong employees had the longest working week out of 71 cities around the world with 50.1 hours a week or 2,605.2 hours a year in 2015 ( $\mathrm{Li}, 2016)$. These results implied long working hour is not only the problem in Japan, however, Japan is still the most serious country of "karōshi". One of the reasons may relate to the work-life balance issue in Japan. Japanese employees are currently entitled to an average 18.5 days' paid holiday a year - only two fewer than the global average - with a minimum of 10 days as well as 15 one-day national holidays. In reality, few come even close to taking their full quota, typically using around half of the total entitlement. They are always struggling whether to take time off to relax, or risk receiving criticism for leaving other colleagues who are still fighting with their work in the company. Majority of annual paid leave they spent counted as sick leave, and the balance of leave was forfeited consequently. In most countries, the length of annual paid leave depends on not only the years of service, but also the position of organization. Unfortunately, Japanese managers are expected to make sacrifice of their personal life by working longer, not to speak of taking more paid leave. Since Japanese women are still necessary to do majority of the child care, this traditional culture has made already unfavorable working conditions of married women in manager even worse. Therefore one of the reasons for Japanese women not wanting to get promoted, according to the 1,058 respondents in the Intelligence survey, is that the inconvenience such a promotion would bring "The position requires longer hours" ( $\mathrm{Su} 2015)$.

\section{2) Gender Difference}

In order to balance the work life and family needs, many Japanese women give up their career when they become mothers. The hurdles they face as they return to work while raising children are compounded by prevalent male-centric practices at many companies which force women to make a tough choice between their families and their careers while leaving men little time to share the housework, as well as the shortage of day care services for their children. It is 
unsurprisingly that the expectation under Japan culture induces the role of women who should be full-time stay-at-home mothers.

According to the survey conducted by the World Economic Forum, covering 144 countries to measure gender equality by analyzing women's participation rates and gaps between men and women in the categories of politics, the economy, education and health, Japan was placed at 114th in the World Economic Forum's global gender equality rankings out of 144 countries, and Japan becomes the worst standing among the Group of Seven major economies (See Figure 6). Although Japan's rating improved in educational attainment due to more women had got higher education, the ranking of economic participation and opportunity was still serious standing at the 114th ranking (Schwab, 2017). The table below lists domestic- and employment-related data for Japan and several leading European countries. Compared to France and Finland, which have high levels of labor equality, Japan's ratio of non-regular employees is disproportionately higher for women at 33.4\% (Figure 7).

\begin{tabular}{|c|c|c|c|}
\hline \multicolumn{4}{|c|}{$\begin{array}{l}\text { Rankings of Gender Gap by region, } 2017 \\
\text { (East Asia and Pacific) }\end{array}$} \\
\hline Country & $\begin{array}{c}\text { Overall } \\
\text { Rank }\end{array}$ & Gountry & $\begin{array}{c}\text { Overall } \\
\text { Rank }\end{array}$ \\
\hline New Zealand & 9 & Indoesia & 84 \\
\hline Philipines & 10 & Cambodia & 99 \\
\hline Australia & 35 & China & 100 \\
\hline Mongolia & 53 & Brunei & 102 \\
\hline Lao PRD & 64 & Malaysia & 104 \\
\hline Singapore & 65 & Japan & 114 \\
\hline Vietnam & 69 & Korea & 118 \\
\hline Thailand & 75 & Jiji & 125 \\
\hline Myanmar & 83 & Timor-Les1 & 128 \\
\hline
\end{tabular}

Figure 6. Rankings of gender gap by region, 2017

Source: The global gender gap report 2017

\begin{tabular}{|l|c|c|c|r|r|}
\hline & \multirow{2}{*}{$\begin{array}{c}\text { Overall Ranking } \\
\text { of Gender } \\
\text { Differene }\end{array}$} & \multicolumn{2}{|c|}{ Nonregular Employment } & \multicolumn{2}{|c|}{$\begin{array}{c}\text { Minutes a day spent } \\
\text { on housework }\end{array}$} \\
\cline { 3 - 6 } & 101 st & $33.4 \%$ & $10.1 \%$ & 299 & \multicolumn{1}{c|}{ Male } \\
\hline Japan & 51 st & $12.2 \%$ & $4.7 \%$ & 296 & 157 \\
Poland & $41 \mathrm{st}$ & $31.1 \%$ & $7.1 \%$ & 315 & 104 \\
Italy & 30 th & $26.5 \%$ & $11.8 \%$ & 254 & 160 \\
Canada & 15 th & $9.7 \%$ & $10.0 \%$ & 233 & 143 \\
France & 3 rd & $16.4 \%$ & $9.5 \%$ & 232 & 159 \\
Finland & & &
\end{tabular}

Figure 7. Housework and nonregular employment: Japan and Leading European Countries

Source: The global gender gap report 2015

Regarding the housework, Japanese men spend nearly only half the amount of time on domestic chores as their overseas counterparts since women are expected to manage all the household decisions. Such findings had shown how traditional gender roles of working husband remain firmly rooted in Japan (Schwab, 2015). On the other hand, loyalty and harmony continue to be stressed and life-long employment system are still prevailing in modern Japan. In particular, men become able to devote themselves to their work when their wife should take care all household work. Therefore, women are considered more suitable to housework and child reading (Yamaguchi, 2000). Kashima Takashi, chair of the Japan Association for the Advancement of Working Women, emphasizes that work culture in Japan still revolves around fulltime male employees working long hours. Many female managers remain either single or are married but without any children so as to have an opportunity to get the position of management (Akira, 2015).

As mentioned in previous paragraphs, men take the main role of work in Japan society. Even though the social demands on Japanese men are changing and some of the stereotypes are not as prominent, "Men-at-work women-at-home" is still 
prevalent and the work-centric way of life for men remains the same. Therefore, it is not surprisingly for women to follow their husband to move to another area if their husband have job relocation or new work, hence it becomes one of the common reasons for women to quit their job after getting married. Most recently, some scholars comment that Japanese corporations with higher performance consistently have greater female participation in senior management, and minimizing the gender gap in Japan may improve the corporate performance, and finally improve Japan's GDP (Wood, 2018, Jiji, 2017).

\section{3) Issue of Babysitter}

The aforesaid discussion has mentioned that most of men will not take the role of child care in Japan society. Certain amount of Japanese women are still eager to participate in labor force if there are some helps available. Meanwhile, Abe's intention of improving women working emphasizes on expanding the number of daycare service centers. However, Japanese women have difficulties to get the support from those centers able to provide long hours service and consequently they cannot stay too late for competing in a male-dominated work environment. Currently, some Japanese families hire helpers from local companies, and majority of them adopt such service on special arrangements such as when house-moving or major-cleaning. Hiring a domestic helper became popular in many countries, however using full-time helpers is still not common in Japan society. The International Labor Organization, a United Nations agency, estimates that the share of domestic workers including Japanese and foreigners is less than 0.1 percent of the total labor force. When this figure compares with about 0.5 percent in the United States and 7.7 percent in Hong Kong, the supply might be far from the demand of domestic helpers in Japan (Twaronite, 2013).

Services of domestic-helper still exist in Japan, but most of them have limited service hours and restricted duties of their service provided. Indeed, it is not easy to sponsor a foreign full-time domestic helper as there are many requirements and limitations, however it is relatively easier and faster to sponsor a helper who is already in Japan as all they need is to change sponsors. In addition, it is not possible to hire a helper who accompanied an expat under the visa category Highly Skilled Professional, as the helper will be required to leave Japan with her employer (Twaronite, 2013). All the strict immigration rules are restricting an abundance of related supply. Actually, some Japanese families already employ foreign workers secretly and illegally, so the change would help to eliminate the grey area and able to legitimize some existing arrangements. Eventually, those Japanese young families can be able to recruit foreign domestic workers (Twaronite, 2013).

Japan's government finally made up their mind to loosen the current tight rules of related immigration in order to obtain more household helpers into the country. The legal change, which was also aimed at easing the problem of labor insufficiency in the housekeeping industry, paved the way for overseas expatriates to work as domestic helper in certain designated areas, including Kanagawa and Osaka since 2017. The objective of the first foreign housekeepers to be employed under a government policy is to assist Japanese professional women re-enter the workforce after having children. Work under the program is limited to such activities as cooking, laundry, cleaning, shopping and child care. The workers cannot be allowed to engage in nursing care.

Heizo Takenaka, a former economy minister who now serves on a government panel on special economic zones stated that the housekeeping program as Japan's first serious attempt at bringing in the required labor force to put the economy on track. Even though immigration opponents fear a rise in crime if rules are eased, he cited Singapore as an example of a country with many foreigners and low rate of crime (Reyonolds \& Aquino, 2017). However, the organized civil force for maintaining order, preventing and detecting crime, and enforcing the laws in Singapore still have certain differences compared with Japan due to the stability of environment. The Japanese government eventually is willing to expand the program nationwide, however, the progress is still slow moving and necessary to expedite. It is believed that such changes are contributable to not only the participation of women in workforce, and also the opportunity of their advancement.

\subsection{Employer's Perspective}

Besides personal considerations, several factors from corporate perspective are also giving working women certain difficulties to climb the career ladder in Japan. The discussions in next paragraphs will include 1) Labor discrimination, 2) Parental leave policy, 3) Expatriation consideration, and 4) Industrial factor.

\section{1) Labor Discrimination Due to Traditional Life Employment System}

Lifetime employment is still a mainstream in most of Japanese companies. They prefer the employees concentrating in their work without any other disturbances. Long service and continuous work are commonly considered the basic requirement to show the commitment of employee to the Japanese company. Career breaks for women managers for child-bearing and child-rearing demonstrate insufficiencies or incompatibilities in terms of management performance, and indicate a deficient in commitment and devotion to work. 
Most Japanese companies have a training system for few years provided for the new graduates after they join the company. Since the training system is based on lifelong employment to develop and it is not favorable to women. On the other hand, around half of major companies will divide employees into two different batches, which include the managerial and general staff. The former usually involves a clear plan for future advancement to management position, while the latter has few chances of promotion and basically staying at the level of general position. In $2012,72 \%$ of companies recruiting employee for a managerial batch requiring transfer between locations indicated that more than $80 \%$ of them were male. Meanwhile, $52 \%$ of companies with a batch of general staff stated that more than $80 \%$ of employees recruited were female. In other words, such system is effectively employed to distinguish manpower by gender. Japan is the only developed country with this kind of loophole is openly in use (Akira, 2015).

For companies with global operations, the relocation is commonly arranged every couple of years. For the case of those women manager who have own families, they find difficulties to leave the spouse or children and transfer to another locations, and finally they will end up quitting their jobs. Therefore, Women are discriminated and not given the same opportunities of overseas assignments as men in terms of position, training, and promotion. Majority of the management positions are only available for men and difficult for women to take up those leadership or senior position in Japan.

\section{2) Parental Leave Policy}

Parental leave is an employee benefit to describe separate family leave available to either parent to care for small children. In order to reflect the national interest in promoting the health and enhance the employee benefit, most high-income economy in the world have several measures or leaves under labor legislation for employees to support parents in their efforts to care for newborn children (OECD.Stat, 2015). Meanwhile, these policies show their concern of well-being of infants and young children as well as society recognition that the first years of child's life are necessary to have substantial care from parents. Japan has some great government programs for parenting leave as well (See Figure 8). These benefits are subsidized by the government instead of the employer. However, the employer has a vital role to manage the system and the union is here with monitoring the mentioned mechanism. In comparison with other countries, both parents can take generous leaves for taking care their children in Japan if they want (Ray, Gornick, \& Schmitt, 2009). The government is set to extend paid child care leave to a maximum of about two years from the current 18 months in Japan. The government hopes to ameliorate the lack of day care spaces across Japan by allowing parents to take more time off work to care for their children. Concerning the length of the leave, each parent can take parental leave, as an individual entitlement, until the child is 12 months old. A parent on leave receives sixty-seven per cent of their salary for the first six months, then fifty per cent of the salary for the remainder. With calculation of full-rate pay, Japan offers very high number of parental leaves for both parents in comparison of other well-developed countries (Ray, Gornick, \& Schmitt, 2009; Fabian, 2014).

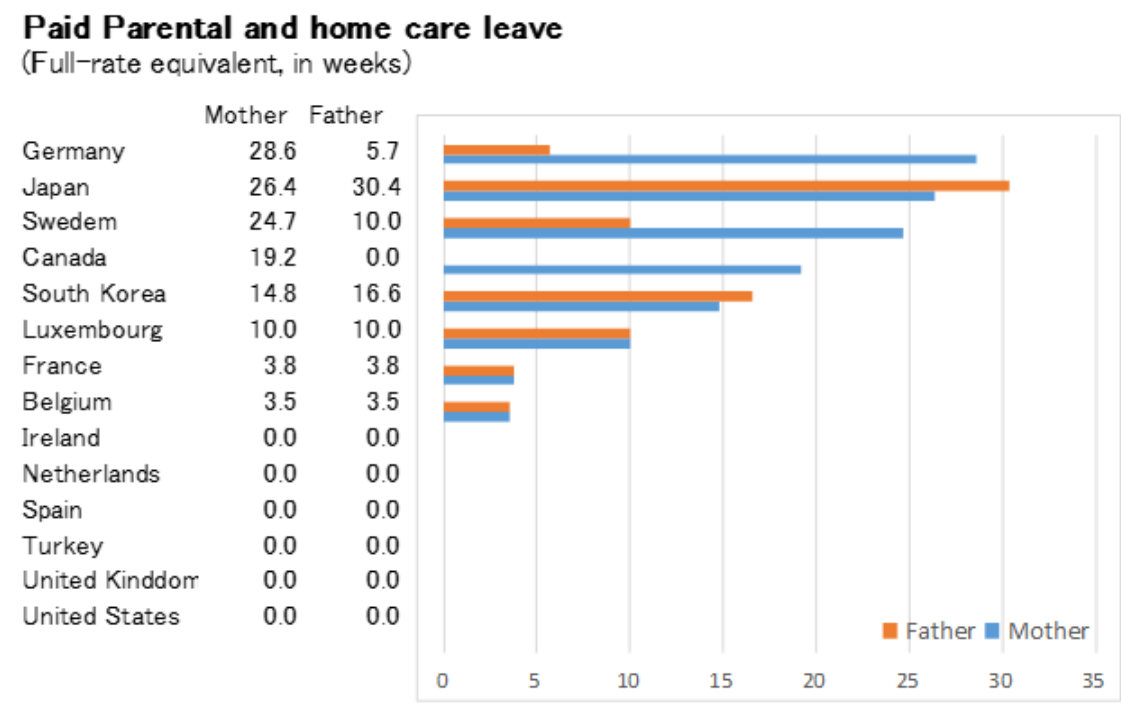

Figure 8. Paid parental and home care leave

Source: OECD Stat (2015)

Traditionally, social expectations have been that women will take on most child care responsibilities. Basically, either father or mother has right to take the parental leave. If child care services are unavailable in their area, the leave can be extended for up to an extra six months. This leave can also be split between the mother and father if they both qualify. Parental leave policies can have a significant effect on gender equality, both in the work area and related to sharing 
child care responsibilities. However, only about $2 \%$ to $3 \%$ of men in Japan take their allotted parental leave. The current attitude of most Japanese men are hesitate to take such benefit even though they want to due to the traditional norm. The continuing prevalence of "pluralistic ignorance" is still restricting men from adopting a positive attitude of taking such welfare (Steger, 2017). On the other hand, it creates strong incentives for women to reduce their employment and take on a large majority of child care responsibilities. The most obvious problems associated with such outcomes are that women suffer a disproportionate burden of child care responsibilities and pay both a short- and a long-term negative influence on the labor market. Although women in Japan is provided with a generous parental leave when they have a child, a look around the average Japanese office might not seem that way. Japanese government has to review the effectiveness of such system. In addition, the gender difference in Japan is far below other developed countries as mentioned in previous paragraphs. It is meaningless that the administration of Prime Minister Shinzo Abe wants to improve this ratio, and set a target to increase the number of men taking paternity leave to 13 percent by 2020 . The generous system of parental leave becomes one of the important reasons for most Japanese companies hesitate to put resources on married women, and finally affect the opportunity of their advancement (Anu, 2014).

\section{3) Expatriation Consideration}

The growth of globalization provides scope for increased economic activity and emergence of transnational corporations as well. The response to global needs and international business have become more complicated so too have the staffing alternatives for the companies involved. Since local expertise are not available, expatriation is commonly used to assign the capable talents from parent countries to work in the host countries for the purpose of knowledge transfer and control of the foreign subsidiaries.

Previous discussions already explained that the considerable barriers which exist for women in Japan moving to senior management positions. Izraeli and Adler (1994) in an extensive review of female managers in the global economy explained that despite an increasing number of capable women looking for managerial positions, the reality remained that the top management team is still highly resistant to women's entry. Even though some companies may be willing to provide opportunities for women through advancing in their domestic managerial rank, few are willing to accept women to expand their career paths through international assignments (Linehan et al., 2003). Such beliefs help create what has been termed the glass border (Mandelker, 1994), which supports the glass ceiling (Morrison and Von Glinow, 1990).

Most top management staffs in Japan may take the family backgrounds of women into consideration of engaging international assignment. A closely related area concerning the conflicting demands of work and home is where there are children involved in the international move since they expect those married women have several concerns of caring their child and house work. Finally, the leader or decision maker of overseas projects will not put the priority on married women to take up those challenges. Work-family conflict is experienced when stresses from the work and family roles are mutually incompatible,

Indeed, there are many successful cases of women expatriates with excellent performance in overseas assignments throughout North America, Singapore, Hong Kong, and Europe. Those capable women expatriates are considered as important talents regardless their gender (Adler, 1987; Westwood \& Leung, 1994) Similarly, research conducted by Westwood and Leung (1994) indicated that there were almost no any barriers to prevent women for further promotion in Hong Kong. However, women in Japan still encounter various obstacles to getting any assignment with overseas challenges. Majority of employees who are expatriated and working in overseas countries are men. Research by Linehand and Scullion (2002) also highlighted that male management staffs in home-country tend not to give women for any chances of expatriation due to the gender difference. The results of research in the United States, by Kleiman (1992), showed that women in junior management are likely to encounter the glass ceiling without even promoting into more senior level. Kanter (1977) also demonstrates that the minimal participation of women in management may be due to blocked opportunities, instead of lack of motivation (Scullion \& Collings, 2006; Sonoda, 2013).

4) Industrial Factor

Although the Japanese companies had accelerated overseas business in previous years, experts expect Japanese manufacturers to continue bringing production home for now as labor costs elsewhere in Asia climb. According to the government-linked Japan Institute for Labor Policy and Training, the manufacturing sector employed $16.7 \%$ of the Japanese workforce in 2015. The figure is the third-highest among advanced nations, behind Germany's $19.3 \%$ and Italy's 18.3\% (JILPT 2015). The U.S., the U.K. and Canada have ratios of around 10\%. Manufacturing industry still contributes a lot of job opportunities in Japan. However, women continue to be under-represented in manufacturing at all levels. Especially, the data and research related to women in manufacturing create a compelling business case for having more women in manufacturing leadership. The workforce continues to be dominated by men, and women are still seen as "different", especially true in manufacturing. Advancing women in organizations is often unfairly influenced by a societal bias that equates leadership with men. Companies that recognize and mitigate these biases by 
developing processes and procedures to promote women to leadership will have a competitive advantage. Several studies show that women leave due to a lack of promotional opportunities, a lack of challenging, novel and interesting work assignments, poor relationships with leaders and co-workers and bias in the workplace.

With reference to Figure 9, the percentage of women in managerial positions from different industries has been shown. The highest rate is $47.2 \%$ for medical care and welfare, and the ratio of male to female is almost 1: 1 . Other industries that exceed the average (and 10\%) are accommodation, food service, life related services, entertainment, education, and learning support. Therefore, it implies that the ratio of women in managerial position can be increased as a whole if government can focus on these industries and take appropriate measures (Minisry of Health, Labour and Welfare, 2014).

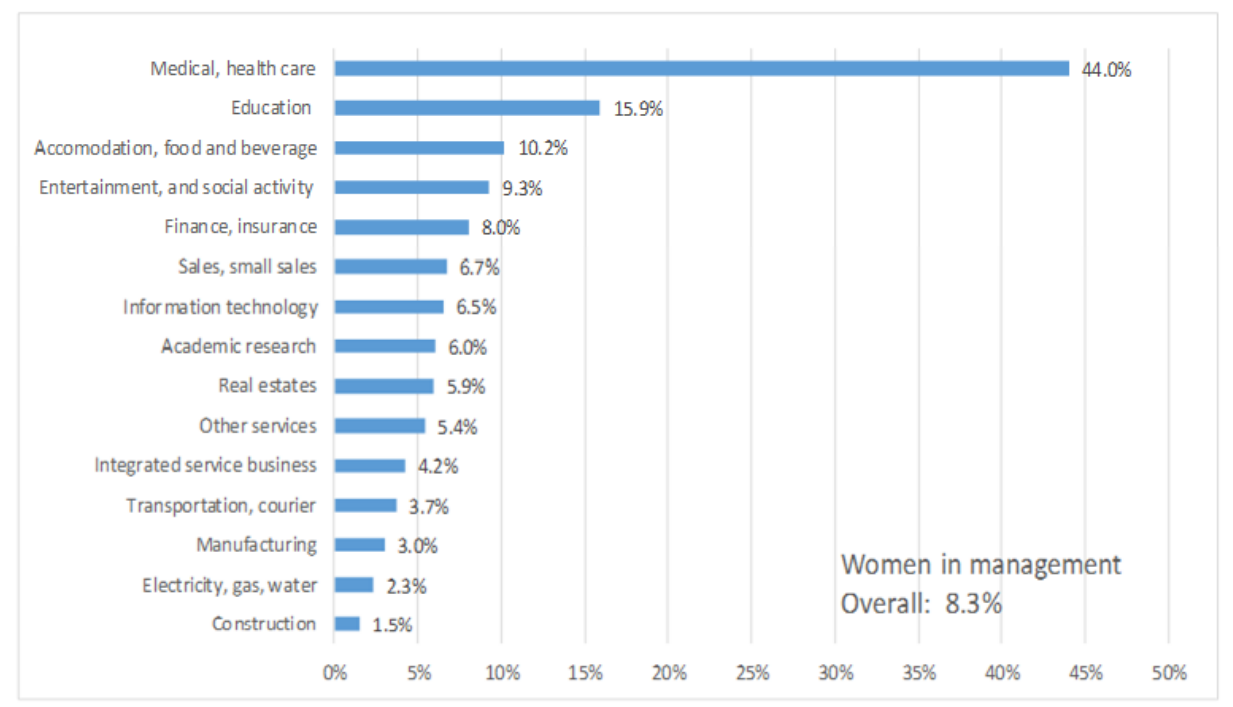

Figure 9. Percent of women in management by industries, 2014 in Japan

Source: Minisry of health, labor and welfare (2014)

Another implication shows that the above difference of female managers' ratio is not only limited to Japan. In U.S., a similar situation can be seen in Figure 10. The shares of women and men were nearly equal among financial managers and property, real estate, and community association managers. Female managers made up less than 20 percent of the manufacturing industries from construction (6.7 percent), architectural and engineering (7.4 percent), and industrial production (18.3 percent). Additionally, 27.9 percent of chief executives were women. Most people are employed in the service industry, commerce, education and administration. Relatively few are in manufacturing and virtually no one is in agriculture (U.S. Bureau of Labor Statistics, 2015). 


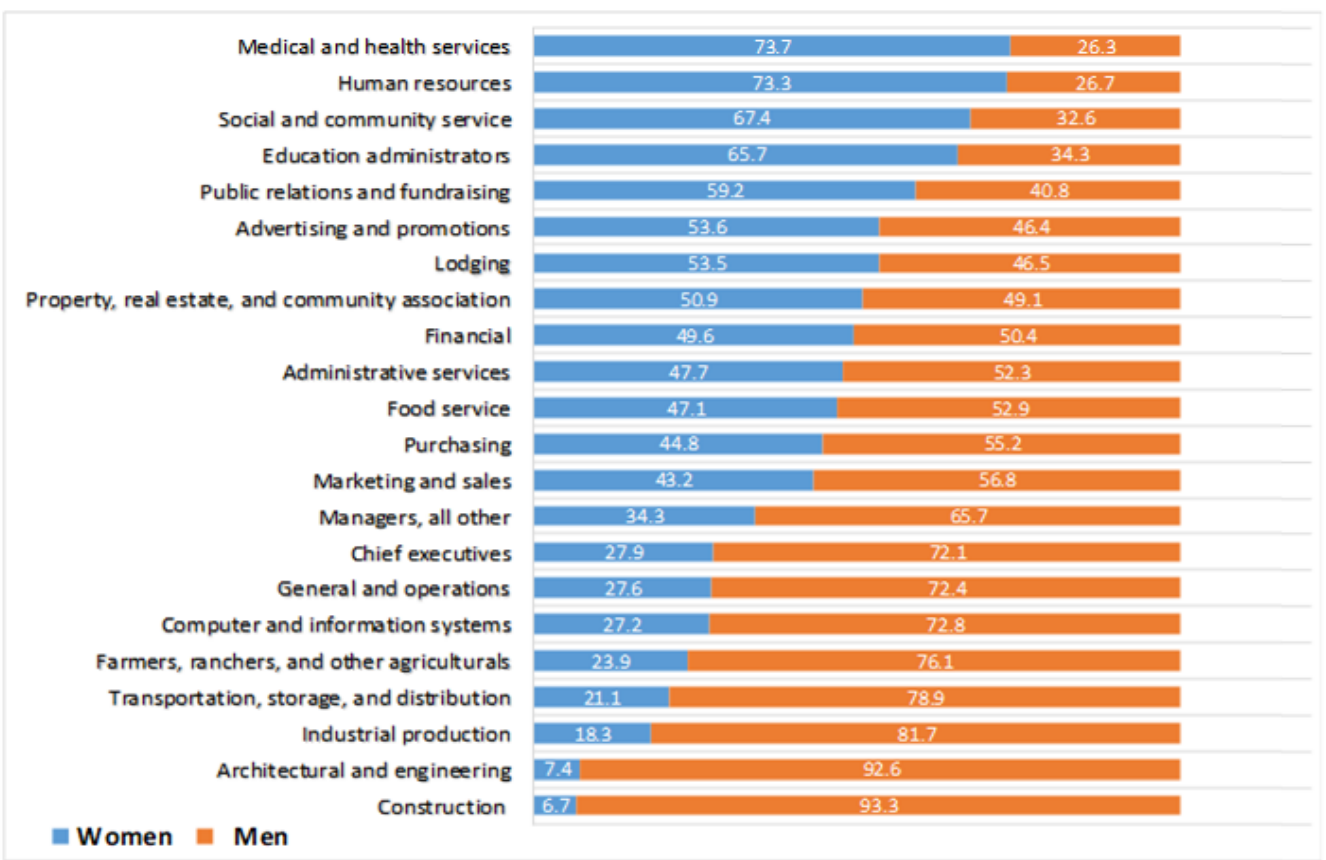

Figure 10. Percent of workers in selected management occupations who were women and men, 2015 in US

Source: US Bereau of Labor Statistics, 2015

Organizational change is not a simple task, and developing an inclusive culture to be considered as one of the most difficult challenges facing manufacturing. Since the increase of women in manufacturing will have a positive impact on the economies, it is necessary to keep continuously figuring out a comprehensive plan to retain or support more women working in this field by making sure those work for women with challenge and interest with clear opportunities to develop their professional skills and competencies. Regardless Japan or other developed countries, the level of women in management is considered with certain difference between servicing industries and manufacturing industries (Nagata, 2015; Buse, 2016).

\section{Methodology}

\subsection{Research Design}

As discussed several difficulties of female as a senior management staff in Japan in comparison with other countries, it will be interesting to have further analysis about those characteristic of company culture will be extended to overseas subsidiaries or not. A research of examining the human resources strategies of Japanese companies in China (JCCs), including the region of Hong Kong and mainland China was conducted in 2017 (Lau, 2018). One of the questions from that survey was that the respondents were asked to show the degree of employing women as management in their companies. Since Hong Kong is one of the metropolitan cities with high equality of gender, and equal opportunities of employment, those Japanese companies may have different pictures for women in management comparing with mainland China. In addition, the nature of industry is considered as one of significant factors to influence the percentage of female manager in an organization. The following analysis will include this factor to analyze the status of gender difference in management position of Japanese companies in manufacturing industries and servicing industries. Based on the above discussions, the following hypotheses have been developed to test the data in the following quantitative analysis.

H1: The percentage of female managers of JCCs in Hong Kong is tend to be higher than those in mainland China.

$\mathrm{H} 2$ : The percentage of female managers of JCCs in service industries is tend to be higher than those in manufacturing industries.

\subsection{Sample and Procedure}

The target organizations in this survey were JCCs, including the region of Hong Kong and Mainland China regardless of type, size, or industry, to ensure an adequate number of responses that could generate meaningful results. Three Japanese organizations including a business consultancy, a recruitment agency, and a Japanese business club were contacted for cooperation and they provided assistance with data collection. A total of 180 valid responses were received for analysis after excluding five which did not meet the inclusion criteria specified for this study. 
Closed-end questionnaire was used in this study and the dependent variables were drawn from features of JCCs. To identify the percentage of gender difference of management positions in all JCCs, potential respondents were asked to indicate the percentage of men/ women in management (Assistant Manager or above) in their companies. Three company attributes: industry sector, age, and size were included as explanatory variables to verify the gender differences of management between various JCCs. Although this analysis was focused on the difference between JCCs in manufacturing sector and service sector, additional verification that included a detailed specific industry analysis was used to provide extra insights. The Industry was identified by a single item selected from a list of 20 possible choices, including automobiles, electric machines, trading, finance, logistic, and so on, which were later grouped into manufacturing and servicing categories. With time, overseas subsidiaries gradually accumulate operational experience, become familiar with operations, decrease the anxiety associated with overseas operations, and reduce the impact of environmental risks. The duration of overseas operation may have an influence on the tendency to employ women in management position. A Japanese MNC company's size is an indication of its investment scale in an overseas operation; it indirectly reflects the contribution of revenue by the parent company in Japan. Larger overseas companies are considered with higher equal opportunities in employment regardless the gender difference. The number of employee is used as a criteria of company size.

\subsection{Measurement}

A "10-point likert-type scale" was used in the question with the aim of collecting related information. The respondents were asked to indicate the percentage of employing women in management in their companies (1: below 10\% women in management, 2: 10\% 20\% women in management, 3: 20\% 30\% women in management, etc). That means the higher score will imply the degree of using women as management staff is higher.

\subsection{Analysis of Data}

This study utilized descriptive statistical analysis to corroborate the data. Microsoft Excel Software package was used to transform primary data into information. In order to fully represent the data analysis, the information was summarized, categorized, and calculated using the mean, standard deviation, and variance (Cooper \& Schindler, 2011). Based on the preliminary result, further quantitative analysis by using T-test for verifying if there is any significant difference between the means of each group of data.

In order to verify whether the years of business and the number of employees have any implication of effect on the degree of using women as management, different groups of age and size of the company were used for further summarization (Table 1 and Table 2).

Table 1. Summary of number of samples

\begin{tabular}{|l|r|r|r|}
\hline & \multicolumn{1}{|c|}{ Hong Kong } & Mainalnd China & \multicolumn{2}{|c|}{ Total } \\
\hline Manufacturing & 29 & 79 & 108 \\
\hline Servicing & $\hat{3} \overline{8}$ & $\overline{3} 4$ & $\overline{\mathbf{1}}$ \\
\hline Total & 67 & 113 & 180 \\
\hline
\end{tabular}


Table 2. Summary of number of samples (By Industry, Years of Business and Number of Employee)

\begin{tabular}{|c|c|c|c|c|c|c|c|c|c|c|c|}
\hline \multicolumn{4}{|l|}{ By Industry: } & \multicolumn{8}{|c|}{ By Years of Business: } \\
\hline & Hong Kong & Mainland & Iotal & & Hong Kong & & & Mainland & & & \\
\hline Manufacturing & & & & & Manufacturing & Servicing & Subtotal & Manufacturing & Servicing & Subtotal & Total \\
\hline Automobiles & 1 & 10 & 11 & 100 or below & 13 & 27 & 40 & 22 & 25 & 47 & 87 \\
\hline Chemical, oil & 5 & 7 & 12 & $101 \sim 500$ & 11 & 9 & 20 & 33 & 9 & 42 & 62 \\
\hline Conveyance machine & 1 & 2 & 3 & $501 \sim 1000$ & 4 & 1 & 5 & 12 & 0 & 12 & 17 \\
\hline Electric, machine & 9 & 38 & 47 & 1000 above & 1 & $\underline{1}$ & $\underline{2}$ & $\underline{12}$ & $\underline{0}$ & $\underline{12}$ & $\underline{14}$ \\
\hline Steel, metal products & 0 & 9 & 9 & Total & $\overline{29}$ & $\overline{38}$ & 67 & $\overline{79}$ & $\overline{34}$ & $\overline{113}$ & $\overline{180}$ \\
\hline Sales - mfg. & 4 & 6 & 10 & & & & & & & & \\
\hline Food and beverage & 2 & 1 & 3 & & & & & & & & \\
\hline Others-mfg & $\underline{7}$ & $\underline{6}$ & $\underline{13}$ & & & & & & & & \\
\hline Subtotat: & $\overline{29}$ & $\overline{79}$ & $\overline{108}$ & By Number of & Employees: & & & & & & \\
\hline Servicing & & & & & Hong Kong & & & Mainland & & & \\
\hline Education & 0 & 2 & 2 & & Manufacturing & Servicing & Subtotal & Manufacturing & Servicing & Subtotal & Total \\
\hline Finance & 4 & 2 & 6 & 5 or below & 3 & 0 & 3 & 4 & 8 & 12 & 15 \\
\hline Information related & 1 & 6 & 7 & $6 \sim 10$ & 1 & 4 & 5 & 15 & 8 & 23 & 28 \\
\hline Insurance & 2 & 0 & 2 & $11 \sim 20$ & 7 & 7 & 14 & 40 & 13 & 53 & 67 \\
\hline Logistic & 6 & 4 & 10 & $21 \sim 30$ & 9 & 12 & 21 & 19 & 5 & 24 & 45 \\
\hline Medical health care & 0 & 1 & 1 & 31 above & $\underline{9}$ & $\underline{15}$ & $\underline{24}$ & 1 & $\underline{0}$ & 1 & $\underline{25}$ \\
\hline Service & 3 & 5 & 8 & Total & 29 & 38 & 67 & 79 & 34 & 113 & 180 \\
\hline Trading & 15 & 7 & 22 & & & & & & & & \\
\hline Other sales & $\underline{7}$ & $\underline{7}$ & $\underline{14}$ & & & & & & & & \\
\hline Subtotal: & 38 & 34 & $\overline{72}$ & & & & & & & & \\
\hline Total & 67 & 113 & 180 & & & & & & & & \\
\hline
\end{tabular}

\section{Results}

First, the preliminary statistical result of their ratings is summarized at the Table 3 . In general, the mean score of total samples is 3.3, which indicates the respondent companies have about $30 \%$ female managers in average in their companies. This result is higher than the average percentage of female managers in Japan. Even though the respondents are also the affiliates of Japanese companies, the gender of manager's distribution in their companies is not fully affected by the traditional culture of Japan. The domestic culture and other factors may pose certain influences on the gender's distribution of management. When we further calculate the data by category of industry (Servicing and Manufacturing) and location (Hong Kong and Mainland China), JCCs in Hong Kong have higher scores compared with those in Mainland China, and JCCs in servicing industry have higher scores compared with those in manufacturing industry respectively. These results tend to be matched with our predetermined hypothesis. However, in Table 4, the length of business operation and the number of employees of JCCs have not shown any direct relationship on the mean scores. Therefore, we focus on the further quantitative analysis of the location difference and the industrial factors to test our hypothesis in next paragraph.

Table 3. Summary of statistical result of analysis

\begin{tabular}{|c|c|c|c|c|}
\hline & Hong Kong & Mainland China & Manufacturing & Servicing \\
\hline Count & 67 & 113 & 108 & 72 \\
\hline Mean & 3.8806 & 2.9558 & 2.9722 & 3.7917 \\
\hline Standard derivation & 2.3324 & 1.8390 & 1.6991 & 2.4777 \\
\hline \multirow[t]{3}{*}{ Variance } & 5.4401 & 3.3820 & 2.8871 & 6.1391 \\
\hline & \multicolumn{2}{|l|}{ Hong Kong } & \multicolumn{2}{|l|}{ Mainland China } \\
\hline & Manufacturing & Servicing & Manufacturing & Servicing \\
\hline Count & 29 & 38 & 79 & 34 \\
\hline Mean & 3.5172 & 4.1579 & 2.7722 & 3.3824 \\
\hline Standard derivation & 1.9932 & 2.5524 & 1.5438 & 2.3615 \\
\hline Variance & 3.9729 & 6.5149 & 2.3833 & 5.5766 \\
\hline
\end{tabular}

\begin{tabular}{|r|}
\hline \multicolumn{1}{|c|}{ Total } \\
\hline 180 \\
3.3000 \\
2.0792 \\
4.3229 \\
\hline
\end{tabular}


Table 4. Summary of statistical result of analysis (By Years of Business, and Number of Employee)

\begin{tabular}{|l|rrrrrr|}
\hline & 5 or below & $\mathbf{6} \sim \mathbf{1 0}$ & $\mathbf{1 1} \sim \mathbf{2 0}$ & $\mathbf{2 1} \sim \mathbf{3 0}$ & $\mathbf{3 1}$ above \\
\hline Count & $\mathbf{1 5}$ & 28 & 67 & 45 & 25 \\
Mean & 3.0000 & 3.3214 & 3.0448 & 3.7333 & 3.3600 \\
Standard derivation & 1.5584 & 2.0194 & 1.8864 & 2.5172 & 2.0591 \\
Variance & 2.4286 & 4.0780 & 3.5586 & 6.3364 & 4.2400 \\
\hline
\end{tabular}

\begin{tabular}{|l|rrrrr|}
\hline & $\mathbf{1 0 0}$ or below & $\mathbf{1 0 1} \sim \mathbf{5 0 0}$ & $\mathbf{5 0 1} \sim \mathbf{1 0 0 0}$ & $\mathbf{1 0 0 0}$ above \\
\hline Count & 87 & 62 & 17 & 14 \\
Mean & 3.6667 & 2.7903 & 3.8235 & 2.6429 \\
Standard derivation & 2.4144 & 1.6310 & 1.7761 & 1.2774 \\
Variance & 5.8295 & 2.6602 & 3.1544 & 1.6319 \\
\hline
\end{tabular}

The group of JCCs located in Hong Kong region $(N=67)$ was associated with the percentage of employing female managers $M=3.88$ ( $S D=2.32)$. By comparison, the group of JCCs located in Mainland China $(N=113)$ was associated with a numerically smaller percentage of employing female managers $M=3.52(S D=2.29)$. On the other hand, the group of JCCs in servicing industries regardless in $(N=72)$ was associated with the percentage of employing female managers $M=3.79(S D=2.48)$. By comparison, the group of JCCs in manufacturing industries $(\mathrm{N}=108)$ was associated with a numerically smaller percentage of employing female managers $M=2.97(S D=1.70)$.

To test the hypothesis that the JCCs located in Hong Kong and Mainland, and those in servicing industries and manufacturing industries were associated with statistically significant different mean respectively, an independent samples t-test was performed. The two-sample t-test is one of the most commonly used hypothesis tests and it is applied to compare whether the average difference between two groups is really significant or if it is due instead to random chance. Note that these hypotheses can constitute a two-tailed test that the null hypothesis will be rejected if the difference between sample means is too big or if it is too small. Due to the sample sizes and variance are unequal in two sample groups, an analytical tool of "T-test Two-Sample Assuming Unequal Variance "in Excel is used for data analysis. The two hypotheses are showed again with stating the null hypothesis and an alternative hypothesis for analysis purpose as below.

Hypothesis 1:

Null hypothesis:

$\mu 1 \mathrm{a}$ (Hong Kong) $=\mu 1 \mathrm{~b}$ (Mainland China) The percentage of female managers of JCCs in Hong Kong is same as those in mainland China.

Alternative hypothesis:

$\mu 1 \mathrm{a}$ (Hong Kong) $>\mu 1 \mathrm{~b}$ (Mainland China) The percentage of female managers of JCCs in Hong Kong is higher than those in mainland China.

Hypothesis 2:

Null hypothesis:

$\mu 2 \mathrm{a}$ (Servicing) $=\mu 2 \mathrm{~b}$ (Manufacturing) $\quad$ The percentage of female managers of JCCs in servicing industries is same as those in manufacturing industries.

Alternative hypothesis:

$\mu 2 \mathrm{a}$ (Servicing) $>\mu 2 \mathrm{~b}$ (Manufacturing) The percentage of female managers of JCCs in servicing industries is higher than those in manufacturing industries.

The testing result is shown in the Table 5. The independent sample t-test was associated with a statistically significant effect, $\mathrm{t}(2.77)=, \mathrm{p}=0.00323$ (one-tail). Thus the JCCs in Hong Kong region were associated with a statistically significant higher mean of female managers than those in Mainland China. Regarding the group of industries, $\mathrm{t}(2.45)=$, $\mathrm{p}=0.00793$ (one-tail) the JCCs in servicing industries were associated with a statistically significant higher mean of female managers than those in manufacturing industries.

Based on these data, we conclude that we can reject the null hypothesis in both cases at the usual significant level of alpha $=0.025$ (one-tail). These results suggest that the mean scores of female managers' percentage of JCCs in Hong Kong region are greater than the mean scores of JCCs in Mainland China, even though both are within China. 
Meanwhile, the mean scores of those JCCs in servicing industries are greater than the mean scores of those in manufacturing industries.

Table 5. Results of t-test: Two-Sample Assuming Unequal Vairances

\begin{tabular}{|l|rr|rr|}
\hline & \multicolumn{1}{|c|}{ Hong Kong } & Mainland & Servicing & Manufacturing \\
\hline Me an & 3.88060 & 2.95575 & 3.79167 & 2.97222 \\
Variance & 5.44007 & 3.38195 & 6.13908 & 2.88707 \\
Observations & 67 & 113 & 72 & 108 \\
hypothe sized Mean Difference & 0 & & 0 & \\
df & 114 & & 115 & \\
$\mathrm{t}$ Stat & 2.77437 & & 2.44859 & \\
$\mathrm{P}(\mathrm{T}<=\mathrm{t})$ one-tail & 0.00323 & & 0.00793 & \\
$\mathrm{t}$ Critical one-tail & 1.65833 & & 1.65821 & \\
$\mathrm{P}(\mathrm{T}<=\mathrm{t})$ two-tail & 0.00646 & & 0.01585 & \\
$\mathrm{t}$ Critical two-tail & 1.98099 & & 1.98081 & \\
\hline
\end{tabular}

\section{Conclusion}

The representation of women in management is a globally controversial issue. In particular, the number of female managers is not showing any significant increase and full of barriers. Cultural problem is considered as one of major obstacle of invisible glass ceiling especially in Japan. Even though many potential female management candidates have excellent qualifications, they are actively ignored and have to face an unbreakable glass ceiling to get any opportunities in the position of senior executive and board positions. After above discussions in various perspective with quantitative analysis, the following part offers a conclusion and gives some hints for further consideration and research.

1) Modify the Target Percentage of Women in Management by Category of Locations or Industries

With the testing result of above analysis, different industries and location have posed various impacts on the decision of employing female managers. Even though within Japan, it is believed that different provinces have certain varieties of culture and development progress. Similar as other overseas countries, companies in manufacturing industries still find certain obstacles in increasing the ratio of female managers in particular. Even some Japanese female supervisors faced unreasonable refusal to follow their instructions or clients, complaining that a woman has been sent and requesting a man instead. Change is underway, and moving slowly. Things maybe even more so from a Western perspective that focus on speed more than Japan's improvement approach to things. Japan government can consider to moderate the target ratio instead of setting $30 \%$ as an overall target in light of different regions or industries. Meanwhile, respective proper action plan should be figured out to pinpoint the problems in each area.

2) Review the Labor Legislation about the Mechanism of Parental Leave

Japan government revised the parental leave mechanism for both mothers and fathers by increasing the entitled percentage of salary and other incentives of taking parental leave. This policy, however, may induce more mothers to have a tendency of extension of leaves in Japan. Even fathers are also encouraged to get the same benefits, as mentioned in previous paragraphs, less than 5\% of them took parental leave. The traditional culture of gender difference may not be easily changed in Japan. Compared with other Asian developed countries, like Singapore and Hong Kong, there are no any similar mechanisms of parental leave. Therefore, above system has to be reviewed and considered how to motivate more women to resume their works after the child is delivered. Meanwhile, the companies may feel easy to assign works and related responsibilities of different tasks to female employees, and hence increase their opportunities of getting promotion. If Japan government intends to improve the employee welfare, the same amount of budget can be allocated to other services like child-care or foreign housekeeping support which will be explained in next paragraphs.

3) Increase the Child Care Support and Domestic Helpers

Even if above proposed modification of labor legislation may improve the work's participation of Japanese women or expedite resuming their duty earlier after the children are delivered, insufficient daycare and after-school care are still one of major concerns for further improvement. There are more than 2 million children are enrolled in childcare centers in Japan, more than 23,000 are still on waiting lists. In order to achieve this goal and improve the insufficiencies, the government had already taken several steps to develop more children centers which will be not only help to moderate the dearth of required service, and also to supply more chances of works for elders. In order to reach this goal, the government had already proposed opening more childcare centers by utilizing a rental system and government-owned 
land; hiring new childcare workers; subsidizing small-scale childcare businesses; assisting unregistered childcare centers seeking registration; and supporting on-site childcare centers on business premises. The government also has to keep continuously to implement measures to increase the availability of after school care for junior school children.

On the other hand, Japan is far behind other developed Asian countries in terms of the usage of foreign housekeepers. Although the communication problems may pose another obstacles to Japanese families to adopt above service, it is necessary to expedite the immigration policies in order to allow more foreign housekeepers in Japan's more special economic zones, not only limited to Tokyo and Osaka. Meanwhile, various subsidies or incentives may encourage more Japanese families to attempt such arrangement.

\section{4) Improve the Work Life Balance}

With reference to above discussions, "karoshi", or death by overwork is still a critical social issues in Japan. Japan government has to strive for promoting a work-life balance by enforcing several new legislations in order to change the traditional work culture of valuing the employee with high productivity in the sense of maximizing output over a period of weeks or months. In 2018, the approved legislation limits overtime work to less than 100 hours a month and fewer than 720 hours a year. On the other hand, another new law had just been approved and will be effective in Apr of 2019 that it governs each employee compulsory to take 5 days paid-leaves per year. It is delighted with those measures to show the government is trying to change the traditional style of work in order to improve the work-life balance, and it is expected certain positive impacts on the labor participation of women including the opportunity of their advancement. However, using a government policy to intervene the work practice is considered as a passive way and not a long term action. If most of the management staff in Japan are still with traditional way of thinking, they will only try to compile the law reluctantly instead of truly reviewing the current work environment and situation to improve the efficiency of work. Therefore companies have to take more measures to educate employees, especially for managers, to recognize the importance of work-life balance.

\section{5) Other Measures}

Several other action plans are still in execution by Japanese government to improve the rate of employing women as management staff. Most of the private sectors are encouraged for promoting more women and supporting the advancement of women. Besides, the government proposes recruiting and promoting more women in government, and supporting female public officials to top-ranking national positions. The Administration has also proposed motivating companies that support female employees to pursue both career and family through subsidies and tax measures. The companies are also encouraged to disclose information concerning the promotion of women to executive and management positions. The Japanese government will require listed companies to disclose the information of women managers' percentage in their financial reports. All those measures still have indirect positive impacts on the overall improvement of the advancement of women.

This paper provides invaluable insights for Japanese government regarding the target percentage of female manager in Japan, with discussions in various perspective and quantitative analysis for hypothesis testing. I hope what this study mentioned will be of benefit to Japanese government in order to figure out more ideas of improvement plans and hence to increase the ratio of female managers more practically. However, it is still necessary to point out the limitation associated with this study. There are no any quantitative analysis on the comparison between different provinces or different industries in Japan. Further work or research in similar approach is needed to continuously execute and confirm the progress of improvement of gender difference in Japan. Since this issue had been discussed numerous times already in past years, it still has a long way for Japan to go even some progress had been made.

\section{References}

Adler, N. J. (1987). Pacific basin managers: a gaijin, not a woman. Human Resource Management, 26(2), 169-93. https://doi.org/10.1002/hrm.3930260205

Akira, K. (2015). Japanese Women Face Tough Reality in Work and Marriage. Nippon.com.

Anu, M. F. (2014). Children not the only cost for working women in Japan. EastAsia Forum.

Baird, C. (2018). Data shows women still struggling to advance in Japan's corporate world. The Japan Times.

Buse, K. (2016). Women in Manufacturing Leadership. Industry Week.

Chanlett-Avery, E., \& Nelson, R. M. (2014). “Womenomics” in Japan: In Brief. Congressional Research Service.

Chia, R. G. (2018). Singaporeans worked almost 9 hours a day in 2018-the lowest in a decade. Business Insider Singapore.

Cooper, D. R., \& Schindler, P. S. (2011). Business Research Methods (11th ed.). New York, NY: McGraw Hill/Irwin. 
Elmuti, D., Jia, H., \& Davis, H. (2009). Challenges Women Face in Leadership Positions and Organizational Effectiveness: An Investigation. Journal of Leadership Education, 8(2). https://doi.org/10.12806/V8/I2/RF4

Fabian, M. (2014). Childcare not the only cost for working women in Japan. East Asia Forum, Economics Politics and Public Policy in East Asia and the Pacific.

Grant, T. (2017). Women in business: New perspectives on risk and reward. Grant Thornton Annual Research, March 2017.

Ikeda, S. (2014). The Factors of Japanese Female Workers' Job Quitting for Childbirth/childrearing. Human Resource Management, Ins. Labour Policy and Training, Tokyo, Japan.

Izraeli, D. N., \& Adler, N. J. (1994). Competitive Frontiers: Women Managers in a Global Economy. Blackwell, Oxford.

Jiji, A. (2017). Japan drops by three to $114^{\text {th }}$ in gender equality rankings by World Economic Forum. The Japan times.

JILPT. (2015). Number of employment in Japan by industry. The Japan Institute for Labour Policy and Training.

Kanter, R. M. (1997). Men and Women of the Corporation. New York: Basic Books.

Kleiman, C. (1992). Right stuff can bump against the glass ceiling. Chicago Tribune, 6(6).

Lau, C. M. (2018). A Comparison of Human Resource Strategies between the Manufacturing and the Service Sector of Japanese Companies in China. Business and Management Studies, 4(2). https://doi.org/10.11114/bms.v4i2.3312

Li, S. (2016). HK has longest working week of 71 cities. CHINADAIY ASIA.

Linehan, M., \& Scullion, H. (2002). Repatriation of female executives: empirical evidence from Europe. Women in Management Review, 17(2), 80-88. https://doi.org/10.1108/09649420210421781

Linehan, M. (2006). Women in international management, In H. Scullion, \& D. G. Collings (Eds.), Global staffing (pp. 178-195). London: Routledge:200-8.

Linehan, M., Morley, M. J., \& Scullion, H. (2003). The management of expatriates: contemporary developments and future challenges. Journal of Managerial Psychology, 18(3), 174-84. https://doi.org/10.1108/jmp.2003.05018caa.001

Mandelker, J. (1994). Breaking the glass border. Working Woman, 19(1), 16.

Ministry of Health, Labour and Welfare. (2014). Overview of wage structure basic statistics survey.

Morrison, A. M., \& Von-Glinow, M. A. (1990). Women and minorities in management, American Psychologist, 45(2). https://doi.org/10.1037//0003-066X.45.2.200

Nagata, T. (2015). Industry and Female Managers. The Japan Institute for Labour Policy and Training. October 20, 2015.

OECD.Stat (2015). Female share of seats on boards of the largest publicly listed companies, Organisation for Economic Co-operation and Development. http://stats.oecd.org/index.aspx?queryid=54753

Ray, R., Gornick, J., \& Schmitt, J. (2009). Parental Leave Policies in 21 Countries: Assessing Generosity and Gender Equality. Center for Economic and Policy Research.

Reynolds, I., \& Aquino, N. P. (2017). Learning to boy: Japan reluctantly opens door to foreign housemaids. The Japan times.

Schwab, K. (2015). The Global Gender Gap Report. World Economic Forum.

Schwab, K. (2017). The Global Gender Gap Report. World Economic Forum.

Scullion, H., \& Collings, D. G. (2006). Global Staffing. Routledge, 178-192. https://doi.org/10.4324/9780203643433

Sealy, R. (2010). Changing perceptions of meritocracy in senior women's careers. Gender in Management: An International Journal, 25(3), 184-197. https://doi.org/10.1108/17542411011036392

Sonoda, A. (2013). Japanese Expatriate Women in the United States. Masters Theses \& Specialist Project. Paper 1319.

Steger, I. (2017). Why almost no men take paternity leave in a country that offers 12 months of it. Quartz.

$\mathrm{Su}, \mathrm{K}$. M. (2015). 75\% of Japanese women not interested in management. Nikkei Asian Review.

Taniguchi, H., \& Kaufman, G. (2013). Gender role attitudes, troubles talk, and marital satisfaction in Japan. Journal of Social and Personal Relationships, 31(7). https://doi.org/10.1177/0265407513516559

Twaronite, L. (2013). Japan household helper plan shows wider immigration dilemma. World News. 
U.S. Bureau of Labor Statistics. (2015). Percent of workers in selected management occupations who were women and men, 2015 annual averages. U.S. Bureau of Labor Statistics.

Westwood, R. I., \& Leung, S. M. (1994). The female expatriate manager experience: coping with gender and culture. International Studies of Management and Organization, 24(3), 64-85. https://doi.org/10.1080/00208825.1994.11656638

White paper. (2018). Gender Equality in Japan, Gender Equality Bureau Cabinet Office.

Wood, J. (2018). Asia's 10 most gender equal countries. World Economic Forum.

Yamaguchi, K. (2000). Married Women's Gender-Role Attitudes and Social Stratification: Commonalities and Differences between Japan and the United States. International Journal of Sociology, 30(2), 52-89.

https://doi.org/10.1080/15579336.2000.11770215

\section{Copyrights}

Copyright for this article is retained by the author(s), with first publication rights granted to the journal.

This is an open-access article distributed under the terms and conditions of the Creative Commons Attribution license which permits unrestricted use, distribution, and reproduction in any medium, provided the original work is properly cited. 